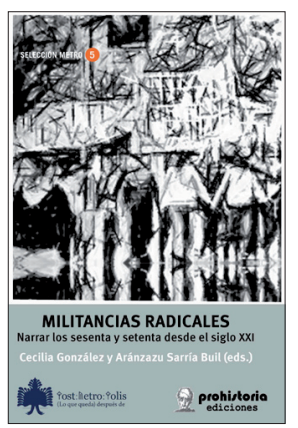

Reseñas

\title{
Militancias radicales. Narrar los sesenta y setenta desde el siglo XXI
}

\author{
Cecilia González y Aránzazu Sarría Buil (eds.)
}

Madrid / Buenos Aires: Postmetropolis Editorial / Prohistoria Ediciones, 2016, 346 páginas.

$\mathrm{n}$ este volumen colectivo se ex-
ploran las militancias radicales, en especial aquellas de los sesenta y setenta (algunas hegemónicas y otras marginales), recuperadas y releídas a fines del siglo XX e inicios del XXI, desde una geografía transatlántica que focaliza en el Cono Sur (Argentina, Chile, Uruguay) y en España (con sus fronteras internas y sus desajustes temporales). Este recorrido supone no sólo una brecha temporal sino un cambio de paradigma político e ideológico tanto en Europa como en América Latina. A nivel global el año 1989, con la caída del Muro de Berlín y el fin de la Guerra Fría, cierra un contexto sacudido por las extremas tensiones entre los bloques socialista y capitalista, y atravesado por revueltas y revoluciones. $\mathrm{La}$ centralidad de la Revolución cubana arma la agenda político-cultural latinoamericana sesentista que, en el Cono Sur, se clausura violentamente con las dictaduras de los setenta. Los inicios de las democracias en los ochenta y noventa trajeron consigo un giro epistémico que dejaba atrás el horizonte revolucionario para introducir el paradigma de los derechos humanos, la democracia y las demandas de la memoria. El caso de España es peculiar ya que su temporalidad está escandida por la Guerra Civil (1936-1939), la dictadura de Franco (1936-1975) y la compleja transición hacia la democracia (iniciada en 1975): sólo hacia finales del siglo XX España hace suya las directrices de los derechos humanos y de la memoria. La relectura o la reinscripción de las militancias radicales de los sesenta se efectúa recién a partir de mediados de los noventa en el sur latinoamericano (y más tarde en España) ya que el relato de los derechos humanos eligió la figura de la "víctima" (invisibilizando al militante) para enjuiciar a los militares bajo el cargo de "violación a los derechos humanos". En esas recuperaciones, sin embrago, no se puede soslayar la fractura histórica y epistemológica que estuvo acompañada por los saberes deconstructivos, articulados en torno a los "post", que hincaban su ojo en las macronarrativas y los relatos épicos. Desde los noventa asistimos a las miradas críticas sobre las militancias radicales, pero 
también a las recuperaciones (reactualizadas) de sus potentes legados, e incluso a particulares momentos en que ambos discursos (los imaginarios revolucionarios de los sesenta y los derechos humanos de los ochenta) coexisten, sin limar sus discrepancias, en raros maridajes.

"Mitos y desmitificaciones" (Parte I) perfila este doble itinerario -deconstructivo y reactualizador- para interrogar los vínculos entre el poder político y su afán mitologizante en determinados escenarios y recorrer las renovadas recuperaciones de los imaginarios militantes. Estornés $\mathrm{Zu}$ bizarreta ("La militancia anti-franquista vasca en la selva de los mitos") explica los "mitos de operatividad política" construidos para legitimar cierto poder inventando una tradición inmemorial y gloriosa. Así, los mitos de "Euskadi, pueblo en marcha" y "España versus Euskadi" característicos del militante vasco antifranquista (presentes en ETA) tergiversaron el lugar que el País Vasco se atribuyó en el contexto de la Guerra Civil Española, exasperando su condición de "víctima", de un "genocidio" contra el pueblo vasco, de una "España contra Euskadi”, a contrapelo de los datos de los documentos históricos. H. Larsen Hansen ("Modos narrativos en la memoria de los movimientos militantes") traza distinciones en el interior de Espańa al preguntarse por qué las narrativas sobre los movimientos militantes antifranquistas escasean en España, mientras en el País Vasco tienen un notable desarrollo. La transnacionalización del discurso del Holocausto y el giro hacia los derechos humanos por parte de la "izquierda cosmopolita", que privilegian a la "víctima” por sobre la figura del "héroe" y debilitan lo político, han provocado la proliferación de novelas sobre la guerra civil y al franquismo. En la literatura vasca, en cambio, la importancia de ETA condujo al desarrollo de narrativas sobre la militancia radical. A partir de tres modos de rememorar el pasado conflictivo (antagonistico, cosmopolita y agonístico), el autor analiza un escaso corpus de novelas españolas sobre la militancia antifranquista que supone una ruptura con el patrón narrativo "despolitizado" del Holocausto, y explora el desarrollo de la abultada literatura vasca sobre la militancia del ETA.

"Mitos, íconos y consignas de la militancia revolucionaria en la narrativa argentina del siglo XXI" de C. González y "Serán ceniza mas tendrán sentido...” de R. Caplán abordan las representaciones culturales sobre la militancia radical en el Cono Sur. González contextualiza fehacientemente el lugar que ha ocupado este tema desde la apertura democrática en Argentina: si en los primeros años del gobierno de R. Alfonsín "los setenta" se silenciaron en una narrativa humanitaria desde la cual se promovieron los Juicios a las Juntas militares privilegiando la figura de la "víctima", es a mediados de la década de los noventa cuando se inicia la recuperación de los movimientos de la izquierda revolucionaria desde otro locus de enunciación caracterizado por la derrota y la cesura epistemológica. Propone cuatro modos de acercamiento a los setenta: el testimonio de los militantes, la producción de la generación de los hijos de los militantes, el empleo de estrategias de distanciamiento y autorreflexividad, y el uso de la parodia para corroer los mitos e íconos de la imaginación revolucionaria. Focalizando en esta cuarta perspectiva, González aborda el análisis en profundidad de Guerrilleros. Una salida al mar para Bolivia (2007), de R. Mira y Montoneros o la ballena blanca (2012), de F. Lorenz desde las matrices genéricas de la distopía y la ucronía, que ponen límites a la ilusión de reconstruir los escenarios del pasado y permiten explorar la presencia del mito como motor de la acción revolucionaria y generador de una subjetividad y una lógica política. Caplán lee en las novelas del uruguayo F. Buttazoni (1953) - El tigre y la nieve (1986) y Las cenizas del cóndor (2014) nuevos modos del relato permeados por el 
tránsito de los setenta revolucionarios, que giraron en torno a la militancia de los Tupamaros, a los noventa de la democracia, silenciados por la Ley de Caducidad de la pretensión punitiva del Estado. Sus novelas dejan de lado, en su relectura de los setenta, las polaridades dominantes en plena Guerra Fría y escapan a los maniqueísmos del momento, para preferir cierta ambigüedad en las posiciones políticas, los vínculos entre víctimas y victimarios, entre prisioneras y torturadores, las líneas porosas entre el Bien y el Mal, el Héroe y el Traidor, la Víctima y el Verdugo, los grises de la historia, las realidades oximorónicas. Caplán visualiza en las novelas de Butazzoni la apertura hacia nuevas líneas en el trabajo de la memoria en Uruguay, tanto frente a los "militantes de la memoria" como a los "traficantes del olvido".

Arqueologias de la resistencia (Parte II) se abre con un acontecimiento seminal de las militancias radicales, las proyecciones de Mayo del 68 como "revolución mundial" en el Cono Sur, diseńando en estas conexiones un mapeo transatlántico. "Mayo del 68 en el Cono Sur de América latina", de S. Boisard, explica las diferencias que este evento fue adquiriendo en los disímiles contextos de Argentina, Chile y Uruguay a partir de varias líneas significativas: la politización de las universidades, las luchas emprendidas por los estudiantes y sus vínculos con los sectores obreros, los procesos iniciados con la reforma universitaria y las crisis en la educación superior, la radicalización de la lucha armada en el contexto de tensiones de la Guerra Fría y el crecimiento del autoritarismo estatal. "La memoria de la militancia universitaria en la narrativa española: una recuperación progresiva”, de A. Florenchie, continúa con el estudio sobre las militancias estudiantiles, pero no ya en su auge durante la década de los 60, sino en su apagón a lo largo de la transición española, explicable por el rechazo hacia el "comunismo" en la agenda internacional y por la imagen negativa del Partido Comunista en España. A través de un variado corpus novelístico, examina la invisibilidad de la militancia estudiantil comunista y antifranquista durante la transición española, y su reemergencia a principios del siglo XXI con el auge de las narrativas de la memoria. Por otro lado, se recuperan militancias marginales, que sólo recientemente logran adquirir un lugar de reconocimiento, militancias "locales" más que "transatlánticas", como el caso del feminismo "demasiado gallego" que retoma I. Touton en "Memoria y legado de las militancias feministas de la transición en la España post-15 M: algunas pistas de reflexión”. Aun cuando fue, para muchos, uno de los movimientos de mayor envergadura durante la transición y motor de cambios sustanciales, la militancia feminista resultó encapsulada en una suerte de alteridad que sólo le reconocía su actuación en el espacio de las luchas feministas peleando por "lo propio" y no en la política más global y nacional. Estas asimetrías iluminan el campo de la transición espańola como una arena de lucha entre las diversas memorias que pugnan por ser reconocidas y muestran las tramas de intereses, poderes, paradigmas no siempre visibles que trabajan en este sistema de inclusión y exclusión. Los artículos aquí reunidos acechan y desmontan la ingeniería de la transición que, para Touton, fue escrita con "traje y corbata". Otra figura de cierta marginalidad ha sido la del militante obrero y anarquista Cipriano Mera recuperado por A. Sarría Buil en "Las memorias de Cipriano Mera, el ejercicio de historiar una militancia política”. La autora exhibe con precisión y complejidad los procesos de construcción de la memoria focalizando en esta figura ejemplar, cuya historia ha sido escrita primero durante los setenta y luego a comienzos del siglo XXI, desplegando diversos "alcances políticos". Durante el gobierno de Franco escribir 
sobre Mera constituía un "acto político" contra la dictadura, luego en la transición su interés cae ante el debilitamiento y la autocrítica de la acción sindical, en cambio en los inicios del siglo XXI resurge con los estudios sobre memoria. Estas idas y vueltas muestran la posibilidad siempre presente de reabrir los relatos sobre la Guerra Civil y el franquismo para introducir nuevas perspectivas, así como el legado de "potencial regenerativo" capaz de alimentar nuevos movimientos sociales.

La Parte III ("Legados y filiaciones") reúne artículos sobre las segundas generaciones e HIJOS de militantes revolucionarios de Argentina y Chile, que permiten ver las diversas elecciones que llevan a cabo frente a la militancia de los padres $\mathrm{y}$ ante las propias militancias en organismos de derechos humanos (en especial en H.I.J.O.S.), así como las renovaciones estéticas. En "La dicotomía público/privado en tela de juicio: dos obras sobre la militancia de los setenta en el Cono sur", I. Logie explora las posiciones de E. Semán en la novela autoficcional Soy un bravo piloto de la nueva China (2011) y de M. Aguiló en el film El edificio de los chilenos (2010). En ambos se advierte una posición de distancia crítica sobre los proyectos revolucionarios de sus padres, esgrimida desde las pérdidas y los costos que esa militancia ocasionó en el espacio familiar y en la vida de los hijos. Advierte la impronta del "giro subjetivo" en estas narrativas: el desplazamiento de lo político hacia la intimidad y el quiebre en la separación entre lo privado y lo público. Los modos de construir estos relatos responden a estos propósitos al cruzar lo autobiográfico o autoficcional con materiales de archivo. La memoria de la militancia estudiantil en el Chile postdictatorial: Av. 10 de junio Huamachuco, de Nona Fernández" de G. Fabry evalúa el fuerte protagonismo que la militancia de estudiantes del secundario tuvo en la dictadura de Pinochet cuando iniciaron en
1983 una ofensiva contra un proyecto de reforma educativa, que consistía en la municipalización de la educación básica y media, y en su conversión en un área regulada por las leyes del mercado (medidas que permanecen intactas en la democracia). En cambio, los rebrotes de estas protestas por la educación durante la transición hacia la democracia (en 2006, 2008 y 2011) adquirieron un carácter más desencantado en un contexto de desmoronamiento del impulso militante, cuando la democracia se desinteresó de las políticas educativas y apartó a los estudiantes del espacio político. No obstante el legado se transmite y "la militancia sigue" asegura Fabry. La autora indaga estos cambios a partir del análisis de algunas crónicas del libro Volver a los 17. Recuerdos de una generación en dictadura, una antología editada por Ó. Contardo en 2013, de la novela $A v .10$ de junio Huamachuco (2007), de N. Fernández y del documental Actores secundarios (2004), dirigido por P. Bustos y J. Leiva.

Erich Fisbach ("Los herederos de la memoria: reconstrucción y deconstrucción en la militancia de la Argentina de los setenta) analiza las perspectivas cuestionadoras de dos HIJAS de padres desaparecidos tanto respecto a la militancia de los progenitores como a la de H.I.J.O.S. Ángela Urondo Raboy esgrimió una crítica a la militancia de los padres y una defensa del derecho de toda generación joven a objetar a los mayores y a buscar su propio destino, lo que le ocasionó un fuerte rechazo en el seno de la agrupación: "Y me fui, eyectada". Mariana Eva Pérez, por su parte, también militó en H.I.J.O.S., pero de un modo complejo y contradictorio. En su libro Diario de una Princesa Montonera - $110 \%$ Verdad (2012) se distancia, con tono burlón y paródico, de los "hijis", combina el término "Princesa" con "Montonera" para mostrar sus diferencias con las militancias de la primera generación ("La Princesa está en las antípodas del fervor 
Montonero pregonado por su padre") y de H.I.J.O.S. ("Ella es todo recato y pensamiento crítico. Detesta El que no salta es un militar"). En "Expansión de la militancia argentina de los sesenta-setenta en el siglo XXI: los hacedores de la memoria", L. H. Mullaly examina -desplegando un recorrido abarcador y al mismo tiempo focalizando en profundidad- las obras de la cineasta A. Carri y de la escritora M. Dillon, ambas hijas de desaparecidos, casadas en 2010 tras la promulgación de la Ley de matrimonio igualitario. Interesadas en bucear en el pasado reciente y sin rechazar las apuestas políticas setentistas de los padres, ambas eligen buscar un modo propio de articular una militancia acorde a sus intereses y a los cambios de coyuntura histórica que convocan nuevos desafíos, muchos de los cuales fueron auspiciados por las políticas de la memoria de los gobiernos kirchneristas. Resulta novedoso el análisis de Mullaly sobre el legado de las "madres" a estas hijas y los vínculos con las actuales militancias femeninas de "Ni una menos". "Pasaje de vida: memoria y representación de la militancia de los padres, de C. Duperron y L. Todeschini, aborda el film Pasaje de vida (2015) de D. Corsini, un hijo de montoneros exiliados en España, quien elige ahondar en dos figuras del militante setentista desde una estética hollywoodense. Se trata de dos personajes diametralmente opuestos: el proletariado con conciencia de clase que llega a la militancia armada por su lucha de sindicalista y la joven burguesa que se proletariza dejando los estudios para trabajar en la fábrica y luchar por un proyecto revolucionario. Ante ambos retratos, este film exhibe una mirada que evita diabolizar al militante como convertirlo en una figura mítica y heroica.

\section{Teresa Basile}

